\title{
PERFIL HEMATOLÓGICO DE OVELHAS SANTA INÊS SUPLEMENTADAS A PASTO NO TERÇO FINAL DE GESTAÇÃO E NO PÓS-PARTO
}

\section{HEMATOLOGICAL PROFILE OF SANTA INÊS EWES SUPPLEMENTED ON PASTURE AT THE LAST THIRD OF PREGNANCY AND POSTPARTUM}

\author{
Fabrício Brandão Pereira ${ }^{1 *}$ \\ Leilson Rocha Bezerra ${ }^{1}$ \\ Carlo Aldrovandi Torreão Marques ${ }^{1}$ \\ Marcos Jácome de Araújo ${ }^{1}$ \\ Jacira Neves da Costa Torreão ${ }^{2}$ \\ Luciana Pereira Machado ${ }^{1}$
}

1 Universidade Federal do Piauí,Centro e Ciências Agrárias, Departamento de Zootecnia, Terezina, PI, Brasil.

${ }^{2}$ Colégio Agrícola de Bom Jesus, Bom Jesus, PI, Brasil

*Autor para correspondência - fa.bricio18@hotmail.com

\section{Resumo}

Objetivou-se avaliar a influência do nível de suplementação com concentrado sobre o perfil hematológico de ovelhas Santa Inês no terço final da gestação e puerpério, assim como dos cordeiros. Utilizaram-se onze ovelhas, aos 75 últimos dias de gestação e nos primeiros 75 dias de lactação e oito cordeiros progênie das ovelhas, distribuídas em delineamento inteiramente casualizado em arranjo de parcelas subdivididas no tempo. As amostras de sangue foram colhidas sempre pela manhã a cada 14 dias. A suplementação não afetou $(\mathrm{P}>0,05)$ o eritrograma e o leucograma dos animais e os componentes sanguíneos avaliados encontraram-se dentro do intervalo de referência para a espécie. A categoria animal influenciou $(\mathrm{P}<0,05)$ os valores de hemácias, observando-se os maiores valores $\left(11,72 \times 10^{6} / \mu \mathrm{L}\right)$ para os cordeiros. Os cordeiros apresentaram valores inferiores $(3073,3 / \mu \mathrm{L})$ de neutrófilos em comparação com as ovelhas, seja na gestação $(4957,6 / \mu \mathrm{L})$ ou no puerpério $(4067,3 / \mu \mathrm{L})$, que não diferiram entre si $(\mathrm{P}>0,05)$. Já na contagem de linfócitos, os valores encontrados nos cordeiros $(2858,8 / \mu \mathrm{L})$ foram semelhantes aos das fêmeas gestantes $(2982,0 / \mu \mathrm{L})$; as fêmeas em lactação $(4119,8 / \mu \mathrm{L})$ apresentaram os maiores valores. A suplementação com concentrado $(0,5 \%$ do PV) no pré e pós-parto não altera o perfil eritrocitário e leucocitário de ovelhas Santa Inês, sendo as maiores diferenças observadas entre as ovelhas das duas categorias e os cordeiros.

Palavras-chave: hemograma; neutrófilos; ovinos nativos; suplementação. 


\begin{abstract}
The purpose of this study was to evaluate the influence of concentrate supplementation level on hematological profile of Santa Ines ewes, at the last third of pregnancy and postpartum, and of their lambs. We used eleven ewes at the last 75 days of pregnancy and the first 75 days of lactation and eight lambs born from these ewes, allotted in a completely randomized design and split-plot arrangement in time. Blood samples were collected every fourteen days. Neither the erythrocyte nor the leukocyte profile was affected by the different levels of supplementation $(\mathrm{P}>0.05)$ and the blood components evaluated were within the reference range for adult sheep. The animal category affected $(\mathrm{P}<0.05)$ erythrocytes, and the highest values $(11.72 \times 106 / \mu \mathrm{l})$ were observed in lambs. Lambs showed lower values $(3073.3 / \mu \mathrm{L})$ for neutrophils in comparison with ewes, during pregnancy $(4957.6 / \mu \mathrm{L})$ or postpartum $(4067.3 / \mu \mathrm{L})$; these values did not differ $(\mathrm{P}>0.05)$. For the lymphocyte count, the values found in lambs $(2858.8 / \mu \mathrm{L})$ were similar to those in pregnant ewes $(2,982.0 / \mu \mathrm{L})$; lactating ewes $(4119.8 / \mu \mathrm{L})$ showed the highest values. Concentrate supplementation $(0.5 \% \mathrm{BW})$ at pre and postpartum does not alter the erythrocyte and leukocyte profile of Santa Inês sheep, with the largest differences between the two sheep categories and lambs.
\end{abstract}

Keywords: indigenous sheep; hemoglobin; neutrophils; supplementation.

Recebido em: 04 dezembro 2013

Aceito em: 23 março 2015

\title{
Introdução
}

A criação de ovinos é bastante difundida no mundo, e esses animais são criados nas mais diversas regiões, muitas vezes, em situações inóspitas tanto nutricionais como ambientais, o que, geralmente, prejudica sua eficiência produtiva e reprodutiva. Nos últimos anos, tem se observado um crescimento significativo da ovinocultura no país em detrimento da criação de animais de grande porte como os bovinos, em consequência das inúmeras vantagens que apresentam como a necessidade de uma menor área de criação, menor ingestão de alimento, facilidade de manejo e uma boa diversidade de produção como carne, leite e couro de boa qualidade.

Em virtude da intensificação dos sistemas, a ovinocultura tem demandado métodos de avaliação metabólico-nutricional, decorrente da maior casuística de doenças metabólicas. Nesse sentido, o hemograma auxilia no diagnóstico e na prevenção dessas doenças, principalmente em animais de alta produção ${ }^{(1)}$. A hematologia como meio semiológico vêm auxiliando no estabelecimento de diagnósticos e acompanhamento dos tratamentos das inúmeras enfermidades que atingem os animais domésticos, tornando-se fundamental o conhecimento dos valores de referência do hemograma dos animais sadios, bem como dos fatores causadores de suas variações. Dentre esses fatores, além da gestação e estado nutricional, merece destaque a significativa influência dos fatores ambientais, havendo uma concordância quase unânime entre os pesquisadores que os animais criados sob diferentes condições edafoclimáticas e de manejo podem apresentar evidentes variações dos elementos constituintes do hemograma ${ }^{(2-4)}$.

Durante a gestação, ocorrem alterações fisiológicas importantes que podem determinar o peso ao nascer e a viabilidade neonatal. Mudanças nos parâmetros hematológicos durante este período ocorrem em diferentes espécies animais e fazem parte da adaptação da fêmea ao período produtivo 
em que ela se encontra ${ }^{(5)}$. Além disso, a gestação, a parição e o puerpério, são fases fisiológicas que demandam uma grande quantidade de nutrientes para o animal bem como para o feto que ele está gerando.

Em virtude dos fatos anteriormente mencionados, objetivou-se, com a realização deste trabalho, avaliar a influência do nível de suplementação no terço final de gestação e início de lactação e da categoria animal (fêmeas em gestação e puerpério e cordeiros) sobre o hemograma de ovelhas Santa Inês criadas a pasto.

\section{Material e Métodos}

Foram utilizadas 11 ovelhas pluríparas da raça Santa Inês, as quais foram submetidas à inseminação artificial. Decorridos 70 dias da inseminação, o diagnóstico de prenhez foi feito por meio de ultrassonografia trans-abdominal (Aparelho Chisson ${ }^{\circledR}$ Mod. 6600, China; transdutor linear 5,0.). Manejo sanitário preventivo foi realizado com vermifugação (o princípio ativo do vermífugo usado foi o Disofenol na concentração de $20 \%$ ) e vacinação (a imunização dos animais foi feita com a vacina polivalente Sintoxan 9HT) contra enterotoxemia, além dos cuidados preventivos de rotina. O período experimental foi de 150 dias, compreendendo os 75 últimos dias de gestação e os primeiros 75 dias de lactação. Durante o período experimental, os animais permaneceram em piquetes de Andropogon gayanus, sendo recolhidos ao final da tarde e alocados em baias individuais medindo $3,75 \mathrm{~m}^{2}$ onde receberam a suplementação concentrada à base de milho moído (70\%), farelo de soja (25\%) e suplemento mineral (5\%), com base na matéria seca (Tabela 1). Os tratamentos foram formados em função do percentual de suplementação concentrada $(0,5 \%$ e $1,5 \%$ do peso vivo), formulada conforme recomendações do Nutrient Requirements Council ${ }^{(6)}$. Semanalmente, todas as ovelhas foram pesadas para o ajuste da suplementação concentrada. As amostras foram moídas em moinho do tipo Wiley, dotado de peneira com perfurações de 1,0 mm para determinação da matéria seca (MS), em estufa a $105{ }^{\circ} \mathrm{C}$, de acordo com os procedimentos gerais descritos por Silva e Queiroz ${ }^{(7)}$.

Tabela 1: Composição química dos ingredientes e do concentrado fornecido às unidades experimentais

\begin{tabular}{lcccccc}
\hline & \multicolumn{7}{c}{ Composição química (\%MS) } \\
\cline { 2 - 7 } Ingrediente & MS & PB & EE & NDT & Ca & P \\
\hline Milho moído & 87,19 & 9,98 & 5,19 & 67,50 & 0,05 & 0,49 \\
Farelo de Soja & 88,48 & 48,76 & 1,75 & 80,73 & 0,33 & 0,57 \\
Suplemento Mineral & 97,91 & - & - & - & 18,00 & 13,00 \\
\hline Concentrado & 88,04 & 19,17 & 4,06 & 67,43 & 1,01 & 1,13 \\
\hline
\end{tabular}

$\mathrm{MS}=$ matéria seca; $\mathrm{PB}=$ proteína bruta; $\mathrm{EE}=$ extrato etéreo; $\mathrm{NDT}=$ nutrientes digestíveis totais; $\mathrm{Ca}=$ cálcio; $\mathrm{P}=$ fósforo. Suplemento Mineral: $10 \mathrm{mg}$ cobalto, $10 \mathrm{mg}$ cobre, $2.5 \mathrm{mg}$ iodo, $580 \mathrm{mg}$ manganês, $0.9 \mathrm{mg}$ selênio, $270 \mathrm{mg}$ zinco e 150 mg ferro.

Além da avaliação da influência dos níveis de suplementação, foram avaliadas três categorias de animais (fêmeas em gestação, fêmeas em puerpério e cordeiros). A partir do momento em que as ovelhas pariram, iniciou-se a coleta de sangue dos cordeiros. Nas fêmeas, as amostras de sangue 
foram colhidas a partir do $75^{\circ}$ dia de gestação até os 75 dias de lactação (momento em que os cordeiros foram desmamados), enquanto que o sangue dos cordeiros foi colhido a partir do primeiro dia de vida e depois a cada quatorze dias. O sangue foi colhido sempre pela manhã, antes de os animais serem liberados para o pasto, por punção da jugular, utilizando-se agulhas hipodérmicas descartáveis $(25 \times 8 \mathrm{~mm})$ e tubos contendo ácido etilenodiamino tetra-acético (EDTA). As amostras de sangue foram mantidas refrigeradas em caixa térmica até o processamento em um prazo máximo de 24 horas.

A contagem do número de hemácias foi realizada em câmara do tipo Neubauer modificada, sendo as amostras de sangue diluídas em solução de Gower; para tal, a diluição das células foi feita utilizando-se pipeta semi-automática de 20 microlitros. Para determinação do volume globular, utilizou-se a técnica do microhematócrito, com o uso de tubos capilares homogêneos de $75 \times 1 \mathrm{~mm}$. A determinação do teor de hemoglobina no sangue foi feita pelo método do cianometahemoglobina. Os valores obtidos com a contagem do número de hemácias, do volume globular e com a determinação do teor de hemoglobina serviram para se estabelecer os valores dos índices hematimétricos absolutos, mediante prévia digitação dos valores em aparelho específico para contagem diferencial de leucócitos.

A contagem do número total de leucócitos foi realizada em Câmara de Neubauer modificada, sendo as amostras de sangue diluídas, na proporção de 1:20, utilizando-se como solução diluidora o líquido de Turk. Com o sangue "in natura" foram distendidos dois esfregaços sanguíneos destinados à contagem diferencial de leucócitos. Esses esfregaços, após secarem, foram corados utilizando-se o corante rápido do tipo Romanowsky (Panótico rápido - LABORCLIN ${ }^{\circledR}$ LTDA, Pinhais, Paraná, Brasil), segundo técnica padronizada para os animais por Viana et al. ${ }^{(8)}$. Em cada esfregaço sanguíneo foram diferenciados 100 leucócitos classificados e lidos em microscópio em aumento de 1000x, de acordo com suas características morfológicas e tintoriais, em neutrófilos, eosinófilos, basófilos, linfócitos e monócitos. A determinação da Proteína Plasmática Total (PPT) foi realizada por refratometria, após a centrifugação do sangue em capilar de microhematócrito.

$\mathrm{O}$ experimento foi conduzido em delineamento inteiramente casualizado. Foram considerados os efeitos de tratamento ( 0,5 e 1,5\% PV de suplementação concentrada) e o efeito de categoria (ovelhas em gestação, em puerpério e cordeiros). As variáveis sanguíneas foram avaliadas pelo arranjo em parcelas subdivididas. A parcela principal constituiu os níveis de suplementação e a parcela secundária, os períodos de colheita, com medidas repetidas no tempo. Os dados foram analisados utilizando-se o Statistical Analysis System - SAS e, para comparação de médias, utilizou-se o teste de Student-Newman-Keuls, com nível de significância igual a 5\%.

O ensaio possui aprovação do Comitê em Ética em Experimentos Animais (CEEA) com o protocolo $\mathrm{n}^{\circ}$ 091/2010.

\section{Resultados e Discussão}

A suplementação concentrada não afetou $(\mathrm{P}>0,05)$ o teor de hemoglobina, hematócrito, número de eritrócitos, volume corpuscular médio, concentração de hemoglobina corpuscular média e proteína de ovelhas da raça Santa Inês em regime de pasto (Tabela 2). 
Tabela 2: Influência do nível de suplementação sobre o perfil eritrocitário de ovelhas da raça Santa Inês no pré e pós-parto em regime de pasto (média \pm desvio padrão)

\begin{tabular}{|c|c|c|c|c|}
\hline \multirow[b]{2}{*}{ Variáveis } & \multicolumn{2}{|c|}{ Nível de suplementação } & \multirow[b]{2}{*}{$\operatorname{Pr}>\mathbf{F}$} & \multirow[b]{2}{*}{ Referência $^{(9}$} \\
\hline & $0,5 \%$ & $1,5 \%$ & & \\
\hline Hemoglobina (g/dL) & $9,79 \pm 1,94$ & $10,12 \pm 1,93$ & 0,366 & $7,5-12$ \\
\hline Hematócrito (\%) & $28,79 \pm 3,23$ & $28,40 \pm 4,36$ & 0,512 & $22-38$ \\
\hline Hemácias $\left(\mathrm{x} 10^{6} / \mu \mathrm{L}\right)$ & $10,18 \pm 1,78$ & $10,71 \pm 2,05$ & 0,123 & $9-11$ \\
\hline $\operatorname{VCM}\left(\mu \mathrm{m}^{3}\right)$ & $28,83 \pm 4,55$ & $27,16 \pm 5,74$ & 0,081 & $26-36$ \\
\hline $\mathrm{CHCM}(\%)$ & $34,15 \pm 6,20$ & $35,71 \pm 6,46$ & 0,179 & $32-36$ \\
\hline $\mathrm{PPT}(\mathrm{g} / \mathrm{dL})$ & $6,79 \pm 0,56$ & $6,95 \pm 1,06$ & 0,148 & $6,5-7$ \\
\hline
\end{tabular}

$\overline{\mathrm{VCM}}=$ volume corpuscular médio; $\mathrm{CHCM}=$ concentração de hemoglobina corpuscular média; PPT = Proteína Plasmática Total;

Médias seguidas de letras distintas diferem estatisticamente $(\mathrm{P}<0,05)$ pelo teste de Student Newman-Keuls; Intervalo de referência para ovinos adultos ${ }^{(9)}$.

A dieta normalmente não é um fator que tem influenciado os parâmetros hematológicos, como observado em outros estudos ${ }^{(9,10)}$. Neste experimento, a redução no fornecimento de energia alimentar suplementar (1,5\% para $0,5 \%$ do peso vivo do animal), também não foi suficiente para alterar os parâmetros hematológicos. Apesar de alguns autores afirmarem que a alimentação inadequada durante a gestação e lactação afeta os parâmetros hematológicos, o que se observou é que, quando as exigências são atendidas, a interferência nos parâmetros é insignificante ${ }^{(1)}$. Em contrapartida, quando os requerimentos nutricionais de ovelhas no pré e no pós-parto não são atendidos, os níveis de hemoglobina e o hematócrito podem apresentar-se diminuídos ${ }^{(4)}$. A deficiência de energia na dieta também está relacionada com baixos níveis de hemoglobina. No caso deste estudo, apesar da diferença entre os níveis de concentrado, acredita-se que as fêmeas não passaram por nenhum tipo de restrição alimentar e tiveram suas exigências nutricionais atendidas, o que explica a semelhança entre os constituintes do perfil eritrocitário. Os componentes sanguíneos avaliados encontraram-se no intervalo de referência para ovinos adultos ${ }^{(9)}$ (Tabela 2).

Pela ocorrência de erros inerentes às tentativas do cálculo de valores médios e desvios padrão da média, a partir de valores apresentados em porcentagens, na apresentação dos resultados da presente pesquisa, optou-se pela utilização dos valores absolutos, aceitando-se, portanto, as recomendações de que essa seria a forma mais representativa para a apresentação dos resultados relacionados ao leucograma ${ }^{(9)}$.

A suplementação concentrada não influenciou $(\mathrm{P}>0,05)$ a contagem total e diferencial de leucócitos totais (Tabela 3). As variações do número de leucócitos e da sua contagem diferencial em ovinos e caprinos têm sido mencionadas na literatura mundial, existindo uma concordância relativa quanto aos efeitos de fatores como parto, gestação, realização de procedimentos cirúrgicos, processos inflamatórios e parasitismo ${ }^{(1,9-11)}$. Entretanto, nenhum trabalho faz menção a alterações do quadro leucocitário quando a dieta é modificada. Na presente pesquisa, não foram observadas modificações no quadro leucocitário quando o nível de suplementação foi aumentado.

A categoria animal influenciou $(\mathrm{P}<0,05)$ a contagem de hemácias, observando-se os maiores valores $\left(11,72 \times 10^{6} / \mu \mathrm{L}\right)$ para os cordeiros (Tabela 4$)$.

O número de eritrócitos em ovinos é variável, sendo influenciado pela idade, raça, condições edafoclimáticas e pelos sistemas de alimentação ${ }^{(12)}$. Observa-se, na literatura, que o número de 
eritrócitos em cordeiros sadios varia do nascimento até os 90 dias de idade, atingindo valores normais a partir desta idade ${ }^{(1,5,9,12)}$. $\mathrm{O}$ volume sanguíneo nesta fase poderá mudar em resposta à circulação útero placentária e ao desenvolvimento do feto. Além disso, o aumento da capacidade eritropoiética em cordeiros provém do maior aporte de nutrientes provido pelo concentrado e pelo leite, em detrimento de uma grande exigência das fêmeas no período de transição (gestação/lactação).

Tabela 3: Influência do nível de suplementação sobre o perfil leucocitário de ovelhas da raça Santa Inês no pré e pós-parto em regime de pasto (média \pm desvio padrão)

\begin{tabular}{|c|c|c|c|c|}
\hline \multirow[b]{2}{*}{ Variáveis } & \multicolumn{2}{|c|}{ Nível de suplementação } & \multirow[b]{2}{*}{ Pr $>F$} & \multirow[b]{2}{*}{ Referência $^{(9)}$} \\
\hline & $0,5 \%$ & $1,5 \%$ & & \\
\hline Leucócitos $(/ \mu \mathrm{L})$ & $8420,70 \pm 2602,34$ & $8014,90 \pm 2982,93$ & 0,459 & $4000-12000$ \\
\hline Neutrófilos $(/ \mu \mathrm{L})$ & $4383,10 \pm 1689,72$ & $4258,80 \pm 1896,37$ & 0,719 & $700-6000$ \\
\hline Eosinófilos $(/ \mu \mathrm{L})$ & $417,14 \pm 330,86$ & $373,17 \pm 355,73$ & 0,529 & $0-1000$ \\
\hline Monócitos $(/ \mu \mathrm{L})$ & $50,23 \pm 106,80$ & $38,22 \pm 70,88$ & 0,510 & $0-750$ \\
\hline Linfócitos $(/ \mu \mathrm{L})$ & $3556,6 \pm 1527,98$ & $3341,4 \pm 1612,75$ & 0,477 & $2000-9000$ \\
\hline Basófilos $(/ \mu \mathrm{L})$ & $67,33 \pm 23,14$ & $64,56 \pm 25,33$ & 0,463 & $0-300$ \\
\hline
\end{tabular}

Médias seguidas de letras distintas diferem estatisticamente $(\mathrm{P}<0,05)$ pelo teste de Student-Newman-Keuls; Intervalo de referência para ovinos adultos ${ }^{(9)}$.

Tabela 4: Influência da categoria animal (fêmea em gestação, fêmea em puerpério e cordeiros) sobre o perfil eritrocitário de ovelhas da raça Santa Inês a pasto e suas crias (média \pm desvio padrão)

\begin{tabular}{lcccc}
\hline & \multicolumn{3}{c}{ Categoria } & \\
\cline { 2 - 4 } Variáveis & Gestação & Puerpério & Cordeiro & Pr>F \\
\hline Hemoglobina $(\mathrm{g} / \mathrm{dL})$ & $9,74 \pm 1,94$ & $10,03 \pm 1,90$ & $10,40 \pm 1,68$ & 0,490 \\
Hematócrito $(\%)$ & $28,61 \pm 3,21$ & $28,41 \pm 2,05$ & $29,15 \pm 3,93$ & 0,716 \\
Hemácias $\left(\mathrm{x} 10^{6} / \mu \mathrm{L}\right)$ & $10,32 \pm 1,99^{\mathrm{a}}$ & $10,15 \pm 1,17 \mathrm{a}$ & $11,72 \pm 1,79 \mathrm{~b}$ & 0,014 \\
$\mathrm{VCM}\left(\mu \mathrm{m}^{3}\right)$ & $28,48 \pm 5,22$ & $28,32 \pm 3,75$ & $25,53 \pm 5,53$ & 0,138 \\
$\mathrm{CHCM}(\%)$ & $34,10 \pm 4,43$ & $35,33 \pm 6,29$ & $36,27 \pm 7,11$ & 0,424 \\
PPT $(\mathrm{g} / \mathrm{dL})$ & $6,93 \pm 0,59$ & $6,72 \pm 0,44$ & $7,09 \pm 0,70$ & 0,077 \\
\hline
\end{tabular}

$\mathrm{VCM}=$ volume corpuscular médio, $\mathrm{CHCM}=$ concentração de hemoglobina corpuscular média, PPT = Proteína Plasmática Total;

Médias seguidas de letras distintas diferem estatisticamente $(\mathrm{P}<0,05)$ pelo teste de Student-Newman-Keuls

Não houve diferença $(\mathrm{P}>0,05)$ entre os valores médios dos eritrócitos das ovelhas na gestação e no puerpério. Em valores numéricos, os menores valores $\left(10,15 \times 10^{6} / \mu \mathrm{L}\right)$ de eritrócitos foram observados para os animais no pós-parto. A redução dos eritrócitos durante o estágio final da gestação tem sido interpretada como efeito da hemodiluição resultante do aumento do volume plasmático. Condições climáticas podem interferir nestas alterações fisiológicas. Em ambiente semiárido, os parâmetros eritrocitários aumentam significativamente, alcançando valores máximos durante o parto e diminuindo após este período ${ }^{(3,4)}$.

Os valores médios do teor de hemoglobina, hematócrito, volume corpuscular médio, concentração de hemoglobina corpuscular média e proteína não diferiram estatisticamente $(\mathrm{P}>0,05)$ entre as três categorias (Tabela 4). Outros autores também não observaram diferenças nos constituintes 
hematológicos entre ovelhas prenhes e lactantes, apesar de evidenciarem que o hematócrito diminui com o avanço da gestação ${ }^{(13)}$.

A categoria animal não influenciou $(\mathrm{P}>0,05)$ a contagem de leucócitos totais, número de eosinófilos e monócitos (Tabela 5); porém, observou-se que os valores de neutrófilos, linfócitos e basófilos sofreram influência do fator categoria. Os cordeiros apresentaram valores inferiores $(3073,3 / \mu \mathrm{L})$ de neutrófilos em comparação com as ovelhas, seja na gestação $(4957,6 / \mu \mathrm{L})$ ou no puerpério $(4067,3$ $/ \mu \mathrm{L})$, que não diferiram entre si ( $\mathrm{P}>0,05)$. Já na contagem de linfócitos, os valores encontrados nos cordeiros $(2858,8 / \mu \mathrm{L})$ foram semelhantes aos das fêmeas gestantes $(2982,0 / \mu \mathrm{L})$; as fêmeas em lactação $(4119,8 / \mu \mathrm{L})$ apresentaram os maiores valores. Os cordeiros apresentaram os menores valores, o que é comum já que os linfócitos tornam-se a classe de leucócitos dominante com o avanço da idade. A relação neutrófilo:linfócito $(\mathrm{N}: \mathrm{L})$ normal em ruminantes adultos corresponde a $0,50^{(14)}$; neste trabalho, a relação $\mathrm{N}: \mathrm{L}$ foi 1,66 nas fêmeas gestantes, 0,99 as fêmeas em lactação e 1,08 nos cordeiros.

A inversão no quadro leucocitário de caprinos com o evoluir da idade, passando de linfocitário para neutrofílico, não se deve apenas à influência da idade, mas reflete também as modificações fisiológicas ocorridas, é o caso de animais gestantes e no puerpério quando essas mudanças são mais notórias $^{(1,9)}$.

As variações do número de leucócitos ocorreram em decorrência do comportamento observado para o número absoluto de linfócitos que diminuíram com a evolução da gestação, tornando o quadro leucocitário predominantemente neutrofílico na fase final da gestação e no puerpério ${ }^{(1)}$. Neste experimento, observou-se uma neutrofilia $(\mathrm{P}<0,05)$ em relação aos cordeiros tanto no período gestacional quanto lactacional; no entanto, essas duas fases não diferiram entre si $(\mathrm{P}>0,05)$ e os valores permaneceram dentro da referência para ovinos.

Tabela 5: Influência da categoria animal (gestação, puerpério e cordeiro) sobre o perfil leucocitário de ovelhas da raça Santa Inês a pasto e suas crias (média \pm desvio padrão)

\begin{tabular}{lcccc}
\hline & \multicolumn{3}{c}{ Categoria } & \\
\cline { 2 - 5 } Variáveis & Gestação & Puerpério & Cordeiro & Pr $>\mathbf{F}$ \\
\hline Leucócitos $(/ \mu \mathrm{L})$ & $8354,20 \pm 2658,69 \mathrm{a}$ & $8725,20 \pm 2976,58 \mathrm{a}$ & $6207,80 \pm 1231,50 \mathrm{~b}$ & 0,015 \\
Neutrófilos $(/ \mu \mathrm{L})$ & $4957,6 \pm 1809,71 \mathrm{a}$ & $4067,3 \pm 1761,30 \mathrm{a}$ & $3073,3 \pm 664,94 \mathrm{~b}$ & 0,001 \\
Eosinofilos $(/ \mu \mathrm{L})$ & $385,95 \pm 319,98$ & $459,53 \pm 373,20$ & $225,27 \pm 288,82$ & 0,104 \\
Monócitos $(/ \mu \mathrm{L})$ & $20,82 \pm 75,86$ & $67,89 \pm 100,97$ & $46,00 \pm 89,55$ & 0,060 \\
Linfócitos $(/ \mu \mathrm{L})$ & $2982,0 \pm 1560,74 \mathrm{~b}$ & $4119,8 \pm 1519,96 \mathrm{a}$ & $2858,8 \pm 907,87 \mathrm{~b}$ & 0,001 \\
Basófilos $(/ \mu \mathrm{L})$ & $27,26 \pm 21,33 \mathrm{c}$ & $55,98 \pm 19,54 \mathrm{a}$ & $38,67 \pm 20,33 \mathrm{~b}$ & 0,005 \\
\hline
\end{tabular}

Médias seguidas de letras distintas diferem estatisticamente $(\mathrm{P}<0,05)$ pelo teste de Student-Newman-Keuls

\section{Conclusão}

A suplementação com concentrado ( $0,5 \%$ do PV) no pré e pós-parto não altera o perfil eritrocitário e leucocitário de ovelhas Santa Inês. Ao se compararem as três categorias, observou-se que as maiores variações dos metabólitos sanguíneos ocorreram entre cordeiros e as duas categoria de fêmeas estudadas, tanto na contagem global de hemácias quanto na contagem global e diferencial de leucócitos. 


\section{Referências}

1. Bezerra LR, Ferreira AF, Camboim EKA, Justiniano SV, Machado PCR, Gomes BB. Perfil hematológico de cabras clinicamente sadias criadas no Cariri paraibano. Ciência e Agrotecnologia. 2008;32(3):955-960.

2. Oladele SB, Ayo JO, Ogundipe SO, Esievo KAN. Seasonal and sex variations in packed cell volume, haemoglobin and total protein of the guinea fowl (Numida meleagris) in Zaria, Northern Guinea Savannah zone of Nigeria. J. Trop. Biosci. 2005;5(2):67-71.

3. Farooq H, Samad HA, Sajjad S. Normal reference Haematolo-gical values of one-humped camels (Camelus Dromedarius) kept in Cholistan desert. J. Anim. Plant Sci. 2011;21(2):157-160.

4. Okonkwo JC, Okonkwo IF, Ebyh GU. Effect of breed, sex and source within breed on the haematological parameters of the Nigerian goats. Online J. Anim. Feed Res. 2011;1(1):8-13.

5. Yaqub LS, Kawu MU, Ayo JO. Influence of reproductive cycle, sex, age and season on haematologic parameters in domestic animals: A review. Journal of Cell and Animal Biology. 2013;7(4):37-43.

6. NRC. National Research Council. Nutrient requirements of small ruminants: sheep, goats, cervids and newworld camelids. Washington: National Academy Press, 2007. 362p. English. www.nap.edu.

7. Silva DJ, Queiroz AC. Análise de alimentos: métodos químicos e biológicos. 3.ed. Viçosa: Editora UFV, 2002. 235p. Portuguese.

8. Viana RB, Birgel Junior EH, Ayres MCC, Biojoni FSM, Souza MCC, Birgel EH. Influência da gestação e do puerpério sobre o leucograma de caprinos da raça Saanen, criados no Estado de São Paulo. Brazilian Journal Veterinary Research Animal Science. 2002;39(4):196-201.

9. Bezerra LR, Torreão JNC, Marques CAT, Machado LP, Araújo MJ, Veiga AMS. Influence of concentrate supplementation and the animal category in the hemogram of Morada Nova sheep. Arquivos Brasileiro de Medicina Veterinária e Zootecnia. 2013;65(6):1738-1744.

10. Luz DO, Lacerda RM, Barreto Júnior RA, Soto-Blanco B. Eritrograma e variantes de hemoglobina em caprinos da raça Canindé. Arquivos Brasileiro de Medicina Veterinária e Zootecnia. 2010;62(1):208-210.

11. Sousa RS, Sousa IKF, Paula V, Barrêto Júnior RA. Alterações hematológicas de ovinos submetidos à implantação de cânula ruminal e orquiectomia. Veterinária e Zootecnia. 2011;18(3):485-487.

12. Gama SMS, Matos JR, Zacharias F, Chaves Filho RM, Guimarães JE, Bittencourt TCBSC, Ayres MCC. Dinâmica do eritrograma de cordeiros, resultantes do cruzamento entre animais de raças nativas criadas no Nordeste e a raça Dorper, desde o nascimento até os seis meses de idade. Revista Brasileira de Saúde e Produção Animal. 2007;8(1):11-23.

13. Brito MA, González FD, Ribeiro LA, Campos R, Lacerda L, Barbosa PR, Bergmann G. Composição do sangue e do leite em ovinos leiteiros do sul do Brasil: variações na gestação e na lactação. Ciência Rural. 2006;36(3):942-948.

14. Addass PA, Perez KA, Midau A, Lawan AU, Tizhe MA. Haemato-Biochemical findings of indigenous sheep breeds in Mubi Adamawa State, Nigeria. Global Vet. 2010;4(2):164-167. 